\title{
Assessing the Readiness and Training Needs of Non-urban Physicians in Public Health Emergency and Response
}

Chiehwen Ed Hsu, PhD, Francisco Soto Mas, MD, PhD, MPH, Holly Jacobson, PhD, Richard Papenfuss, PhD, Ella T. Nkhoma, MPH, and James Zoretic, MD, MPH

Emergency readiness has become a public health priority for United States communities after the 9/11 attacks. Communities that have a less developed public health infrastructure are challenged to organize preparedness and response efforts and to ensure that health care providers are capable of caring for victims of terrorist acts. A survey was used to assess nonurban physicians' prior experience with and selfconfidence in treating, and preferred training needs for responding to chemical, biologic, radiologic, nuclear, and explosive (CBRNE) cases. Data were collected through a mailed and Webbased survey. Although the response rate was calculated at 30\%, approximately one third of the surveys were not able to be delivered. Most respondents reported never having seen or treated CBRNE-inflicted cases and were not confident in their ability to diagnose or treat CBRNE cases, but many were willing to participate in a state-led response plan. Almost half of the individuals had not participated in any related training but expressed interest in receiving training in small group workshops or through CD-ROM. These results provide potential direction for strategic preparedness planning for non-urban health care providers.

Chiehwen Ed Hsu, PhD, is Assistant Professor of Public and Community Health, University of Maryland, College Park, and Adjunct Faculty of School of Health Information Sciences, University of Texas Health Science Center, Houston. Francisco Soto Mas, MD, PhD, MPH, is Assistant Professor of Social and Behavioral Sciences, School of Public Health, University of North Texas Health Science Center, Fort Worth. Holly Jacobson, PhD, is Assistant Professor of Social and Behavioral Sciences, School of Public Health, University of North Texas Health Science Center, Fort Worth. Richard Papenfuss, $\mathrm{PhD}$, is Director, Center for Health Promotion, University of Nevada, Las Vegas. Ella T. Nkhoma, MPH, is Doctoral student of Epidemiology, University of North Carolina at Chapel Hill. James Zoretic, MD, MPH, is Medical Director of Texas Department of State Health Services Region 2 and 3, Arlington. errorist events pose risks and challenges to all health care providers. The ability of the United States Public Health System to respond to emergencies caused by terrorist events has become a renewed major concern since the September 11, 2001, tragedy and the ensuing anthrax attacks. ${ }^{1,2}$ These events revealed potential weaknesses in the United State's emergency response systems, and future chemical and biologic terrorist acts would challenge the local level systems. ${ }^{3-5}$ Currently, the state and local jurisdictions are not considered to be sufficiently prepared to respond to a bioterrorist attack because of inadequate planning and insufficient communication networks. ${ }^{6,7}$ All components of the public health infrastructure, including the primary providers and systems used to identify them, need to be evaluated to determine if the system can manage a local disaster.

\section{State and local jurisdictions are not considered \\ to be sufficiently prepared to respond to a bioterrorist attack....}

Health care providers are a part of the public health infrastructure and need to be aware of how they can respond to potential emergency events. Non-urban

Support for the completion of this study was provided by Texas Department of State Healthcare Services ( formerly the Texas Department of Health) through the project entitled Survey of Physicians, Other Health Professionals and Providers for Emergency Response Purposes awarded to Chiehwen Ed Hsu, PhD.

The opinion and analysis in this article are solely the authors' and do not reflect the views of the agencies or institutions the authors serve.

Reprint requests: Chiehwen $\mathrm{Ed} \mathrm{Hsu}, \mathrm{PhD}$, University of Maryland-College Park, 2371 HHP Building, Valley Drive, College Park, MD 20742; E-mail: edhsu@umd.edu.

Disaster Manage Response 2005;3:106-11.

$1540-2487 / \$ 30.00$

Copyright (C) 2005 by the Emergency Nurses Association. doi:10.1016/j.dmr.2005.07.001 
counties could be more vulnerable to bioterrorism because of their lack of resources (eg, limited availability of health services, lack of coordinated effort, and a high number of commuters living in these communities) and their distinct geographic characteristics (eg, rough terrain and downwind of airborne spread of infectious agents). ${ }^{5,8}$ In addition, non-urban health care providers may have limited experience with chemical, biologic, radiologic, nuclear, and explosive (CBRNE) agents.

The literature suggests that physicians can play a unique role in public health preparedness because they are among the most trusted first receivers in a health-related incident, including CBRNE-inflicted events. ${ }^{2-5,9}$ Physicians may assist health officials in dealing with patients who experience fear, confusion, concerns, and psychological stress that normally arise in disasters and that often present significant management and emotional challenges. ${ }^{10-12}$ In addition to providing early detection, treatment, and reporting, physicians can actively report and collaborate with public health authorities to help augment services. ${ }^{2,4,13}$

Many health care providers lack competence in handling CBRNE-related cases. ${ }^{2,14-16}$ A national survey revealed that whereas $80 \%$ of physician respondents were willing to participate in the diagnosis and treatment of bioterrorism cases, only $21 \%$ believed that they were prepared to handle the cases. ${ }^{17}$ The challenge for emergency preparedness planners is to determine how they can provide training to busy practitioners who are located away from traditional educational centers. One study found that most physicians preferred hands-on type courses, Web-based activities, or interactive CME courses rather than large classroom, formally structured lectures. ${ }^{14}$ Another study found that screen savers and

\section{The challenge for emergency preparedness}

planners is to determine how they can provide

training to busy practitioners who are located

away from traditional educational centers.

Web sites can be used to enhance bioterrorism awareness, and Web-based education may provide an effective means of bioterrorism education to an audience of health care providers. ${ }^{18}$ It thus appears that there are specific training approaches that would be optimal in delivering preparedness training to this group. In an effort to identify how to improve CBRNE preparedness and training for non-urban health care providers, a study was done to assess the bioterrorism-related experience and the training needs of non-urban physicians. Although it was not an original goal of the study, this survey also assessed the ability to use the database provided by the state licensing board to contact physicians with regard to emergency preparedness.

\section{Materials and Methods}

A cross-sectional design survey was done that included physicians practicing in 37 North Texas counties and who were registered with the Texas Medical Board.

\section{Subjects}

A physician database was obtained from the Texas State Board of Medical Examiners that included demographic information, practice status, and location. A potential survey population of 841 physicians in the targeted geographic area was identified. The unit of analysis and observation for this study consisted of the individual physician. The main selection criteria for inclusion were: (1) licensed physician (included actively practicing and retired), and (2) practicing or residing in a preselected nonurban county. The study was built on a collaborative partnership between the University of North Texas Health Science Center School of Public Health (UNTHSC) and the Texas Department of Health (TDH).

\section{Setting}

The physicians contacted for the survey practiced or resided in one of 37 selected counties in North Texas. Most of the counties were classified as "nonparticipating," meaning that they did not have a local health department and were of a non-urban nature.

\section{Survey Instrument}

The survey instrument was developed by the research team through a review of the literature and approved by the Institutional Review Boards of both TDH and UNTHSC. Survey instruments described in the CBRNE-related literature were identified ${ }^{2,19}$ and used as references. The survey instrument was pilot tested with a small number of physicians who were not part of the study population, and feedback was gathered. The final version was posted on the University Web site (available from: URL: http://www.hsc.unt.edu/departments/ SPH/survey/biot.cfm?form.id\&form.ln).

\section{Data Collection Procedures}

Data were collected through both a mailed survey to the 841 physicians who met the selection criteria and a Web-based survey. The cover letter included a description of the survey, human subject protection information, and a brief discussion on the importance of the study. The URL of the online survey was also 
included in the cover letter for those who preferred to complete it online.

The Web-based survey was accessible to participants through a personalized authentication system that used a code provided to each participant in the mailed package and was required for log-in to the system. The server verified participants' information before allowing them access to the survey Web page.

Completed online survey information was automatically saved to a database. The data entered were then collected and stored in a relational database that was linked to the corresponding physicians' license numbers. Two weeks after the initial mailing, a reminder postcard was mailed to physicians in counties for which no survey had been received, and a week later, a second survey package was sent to all physicians for whom a completed survey had not yet been received.

\section{Data Analysis}

Data were analyzed using SPSS 11.5.0 (Chicago, Ill; SPSS, Inc, 1989-2002). The analyses included simple descriptive statistics to determine the distribution of responses regarding research questions of interest. Additionally, to compare the characteristics of respondents and nonrespondents, the $t$ test was used for the analysis of continuous response variables, and the $\chi^{2}$ test was used for categorical response variables. Choropleth (color-shaded) maps were used to summarize survey results by county, which highlighted the number of physicians with experience in public health emergency care and the training needs in the region.

\section{Results}

Approximately $67 \%$ (559 out of 841) of the identified physicians who were mailed a survey package were actually contacted. As a result of using the state licensing board database and listed addresses, more than $33 \%$ of mailed packets were found to have a wrong address and were returned. Out of the 559 physicians who did receive a package, only 163 (30\%) returned packages, and additionally, 3 physicians chose to complete the survey on the Web. Of the 163 surveys that were completed and returned by mail, $12.3 \%$ were received in response to the second reminder mailing. Table 1 presents the demographic characteristics of the physician respondents.

\section{Demographics}

Most respondents (82.8\%) were male; they had a mean age of 50.2 years, and a majority listed themselves as non-Hispanic whites (79.1\%). The physicians reported that they had a private practice

\begin{tabular}{|c|c|c|}
\hline Characteristic & $\begin{array}{l}\text { Respondents } \\
(\%)\end{array}$ & $\begin{array}{l}\text { Non-respondents } \\
(\%)\end{array}$ \\
\hline \multicolumn{3}{|l|}{ Sex } \\
\hline Female & 17.2 & 21.1 \\
\hline Male & 82.8 & 78.9 \\
\hline Age (mean) (y) & 50.2 & 50.4 \\
\hline \multicolumn{3}{|l|}{ Race/ethnicity } \\
\hline $\begin{array}{l}\text { Non-Hispanic } \\
\text { white }\end{array}$ & 79.1 & 77.9 \\
\hline Black & 0.6 & 3.0 \\
\hline Hispanic & 4.9 & 3.6 \\
\hline $\begin{array}{l}\text { Asian American } \\
\text { or PI }\end{array}$ & 13.5 & 12.9 \\
\hline $\begin{array}{l}\text { American Indian } \\
\text { or Alaskan Native }\end{array}$ & 1.2 & 0.8 \\
\hline \multicolumn{3}{|l|}{ Degree } \\
\hline MD & 81.5 & 73.0 \\
\hline $\mathrm{DO}$ & 18.5 & 27.0 \\
\hline \multicolumn{3}{|l|}{ Practice setting } \\
\hline $\begin{array}{l}\text { Veterans Affairs } \\
\text { hospital }\end{array}$ & 1.9 & 1.9 \\
\hline Hospital & 15.5 & 15.8 \\
\hline Private practice & 43.2 & 45.4 \\
\hline Partnership/group & 37.4 & 33.4 \\
\hline Other & 1.9 & 3.6 \\
\hline
\end{tabular}

(43.2\%) or a group practice $(37.4 \%)$ or were employed by a community hospital (15.5\%) or a Veteran's Affairs hospital (1.9\%). The participants represented 28 (75\%) of the 37 non-urban counties served by the Department of Health Regional Office, and more than $80 \%$ of the counties with one or more practicing physician.

To determine if there were any demographic differences between respondents and nonrespondents, an independent samples $t$ test was conducted on the age variable using response status as a predictor variable. For categorical variables, $\chi^{2}$ was used to determine differences in sex, practice setting, primary specialty, type of medical school degree (DO vs MD), and ethnicity by response status. The results indicate that there were significant differences in response status by medical school degree; physicians with a DO degree had a substantially higher response rate than did physicians with an MD degree $\left(\chi^{2}=4.98, P=\right.$ .026). No significant differences at the $95 \%$ confidence level were found between respondents and nonrespondents for the remaining response variables.

\section{Reported Experience With CBRNE}

The majority (79.1\%) of respondents reported that they had neither seen (79.1\%) nor treated (81.6\%) CBRNE exposures. A few physicians $(\mathrm{n}=34$, $20.9 \%)$ reported having seen or treated $(\mathrm{n}=30$, $18.4 \%)$ chemical exposure/infectious diseases that 
Table 2. Respondents who have seen and treated a case of public health emergency

\begin{tabular}{|c|c|c|c|c|c|}
\hline \multirow[t]{2}{*}{ CBRNE event } & \multicolumn{2}{|c|}{ Seen } & \multicolumn{2}{|c|}{ Treated } & \multirow[b]{2}{*}{$\begin{array}{c}\text { No answer } \\
n(\%)\end{array}$} \\
\hline & $\begin{array}{c}\text { Yes } \\
\text { n }(\%)\end{array}$ & $\begin{array}{c}\text { No } \\
\text { n (\%) }\end{array}$ & $\begin{array}{c}\text { Yes } \\
\text { n }(\%)\end{array}$ & $\begin{array}{c}\text { No } \\
\text { n (\%) }\end{array}$ & \\
\hline Anthrax & $4(2.5)$ & $159(97.5)$ & $3(1.9)$ & $160(98.2)$ & $3(1.9)$ \\
\hline Botulism & $8(4.9)$ & $155(95.1)$ & $8(4.9)$ & $154(94.5)$ & $3(1.9)$ \\
\hline Smallpox & $8(4.9)$ & $155(95.1)$ & $4(2.5)$ & $159(97.5)$ & $3(1.9)$ \\
\hline Plague & $3(1.8)$ & $160(98.2)$ & $2(1.2)$ & 160 (98.8) & $3(1.9)$ \\
\hline Chemical exposure & $34(20.9)$ & $129(79.1)$ & $30(18.4)$ & $133(81.6)$ & $3(1.9)$ \\
\hline Radiologic exposure & $7(4.3)$ & $156(95.7)$ & $4(2.5)$ & $159(97.5)$ & $3(1.9)$ \\
\hline
\end{tabular}

were related to their experience in foreign wars (see Table 2).

\section{A few physicians $(n=34,20.9 \%)$ reported having seen or treated $(n=30,18.4 \%)$ chemical exposure/infectious diseases that were related to their experience in foreign wars}

\section{Training Needs}

The majority ( $\mathrm{n}=118,72.4 \%)$ of physicians in this survey reported that they had not participated in CBRNE preparedness and response training. Of those who had received training, they had done so after September 11, 2001 , and had received more than one type of training. Many respondents (45.8\%) reported that they would be willing and available to collaborate with the TDH when a CBRNE incident occurs.

The realities of preparing for a potential event and handling a busy daily practice may have been a factor for many respondents. Although the majority (72.4\%) of respondents reported that they would like to receive additional information or materials on CBRNE, only a few (9.2\%) reported that they would be willing to participate in formal training in either instructor-led, small group workshops or large group presentations. Respondents also indicated interest in other types of educational offerings, such as CD-ROM-based training (31\%), audiovisual instructor-led training materials (26\%), curriculum-based reading materials (23\%), Internet-based training (18\%), and self-paced professional/scientific journals and publications (14\%) (see Figure 1).

\section{Discussion}

\section{Assessing Experience}

Many physicians who participated in this study were willing and able to contribute to state-level
CBRNE preparedness and response efforts and wanted to receive additional information or materials. The majority of respondents reported not feeling confident in their ability to handle CBRNE cases, which is a consistent finding with other studies. ${ }^{2,15,17}$ Most physicians had not participated in any type of training to improve their confidence.

\section{Training Needs}

Physicians often have competing demands for their time, and it was not surprising that only a few of those surveyed indicated a willingness to participate in formal training. This finding is consistent with a previous report, ${ }^{14}$ and both studies underscore the importance of developing "tailored educational offerings" for continuing medical education.

Physicians stated a preference for learning in small group, tailored workshops rather than large group, structured lectures or presentations. This finding also is consistent with the literature. ${ }^{20-22}$ Training consisting of CD-ROMs, scientific publications, audiovisual materials, and instructor-led, small group workshops are recommended.

\section{Limitations}

As noted, the survey response rate was relatively low and may have been a reflection of the physician's interest in the subject matter or motivation to respond to a survey. The potential for generalizing the results of this needs assessment study is constrained by the low response rate and the fact that it only included physicians in non-urban Texas counties. However, the results are generally consistent with published literature.

\section{Implications for Future Research}

This study had several additional important implications for future research.

1. The State Medical Licensing Board database was found to be less than reliable. More than 33\% of mailed surveys were returned because of wrong or outdated addresses. This occurred even with the most recently updated version of 2004 


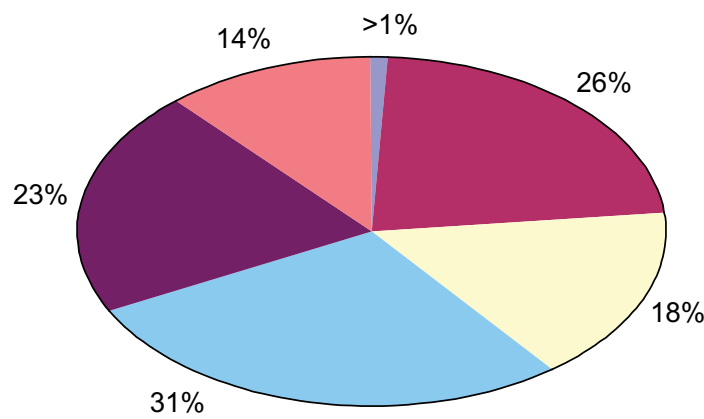

Note: this question allowed multiple choices

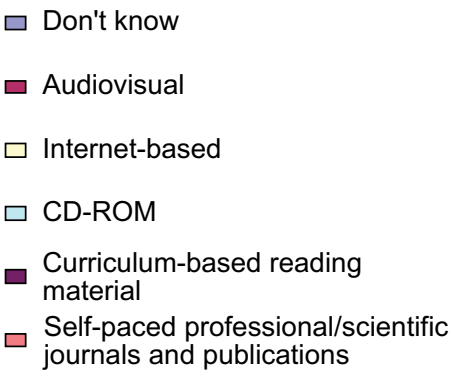

Figure I: Preference of training format.

database and is a relevant issue because state health authorities and/or emergency preparedness planners will need to be able to access all practitioners, in addition to physicians, for mass casualty planning. Future research should explore how contact data are managed.

2. A database is needed to identify which physicians have expertise with various CBRNE agents. It is especially important in non-urban areas where personnel and education are limited to be able to develop a database that catalogs available resources. The database could include experience with the diagnosis and treatment of infectious diseases, especially Category A agents, such as anthrax, small pox, botulism, and plague. The ideal format would be an electronic database in a Web-based GIS format that allows for routine update and dynamic query of information.

\section{A database is needed to identify \\ which physicians have expertise with various CBRNE agents.}

3. Physicians demonstrated a low utilization of/ response to the Web-based survey. It is possible that non-urban physicians are less responsive to Web-based survey instruments, or they may be missing an important communication channel for risk communication, especially in relatively isolated geographic regions. Although other studies have suggested that Web sites can be used to enhance CBRNE awareness, and Web-based education may provide an effective means of CBRNE education to an audience of health care providers, ${ }^{18}$ our study suggested that the Web may not be the most effective communication method or means for data collection for nonurban physicians.

4. Although this study focused on physicians in nonurban settings, the results may prove beneficial for health care providers in general, including those practicing in urban areas. Many clinicians lack CBRNE-related awareness, knowledge, and experience, and additional studies should explore these issues. The findings of this study present the challenges and opportunities of developing coordinated strategies to strengthen the preparedness education, planning, and response of state health departments and non-urban health care providers.

5. The role that non-urban physicians should play in emergency preparedness warrants further study, considering the scarcity of literature dealing with this subject matter.

\section{Conclusions}

Although this survey had a moderately low response rate, the findings are consistent with other reports in the literature. This study found that most non-urban physicians in North Texas have limited experience with CBRNE events, are not confident in the diagnosis and treatment of CBRNE-associated cases, and have yet to receive adequate biodefense training. Respondents who indicated an interest in additional training preferred instructor-led, small group workshops, self-paced CD-ROM modules, professional/scientific journals and publications, and audiovisual training materials. Many respondents are willing to participate in a state-led response plan. State planners should evaluate methods used to communicate with health care providers and to document their skills and expertise if they are needed for assisting with unusual medical events.

Acknowledgment: We would like to extend appreciation to the 166 physicians of non-urban North Texas counties who participated in the survey.

\section{References}

1. Clawson A, Brooks R. Protecting rural communities from terrorism: a statewide, community-based model. J Rural Health 2003;19:7-10. 
2. Chen F, Hickner J, Fink K, Galliher J, Burstin H. On the front lines: family physicians' preparedness for bioterrorism. J Fam Pract 2002;51:745-50.

3. United States General Accounting Office. Bioterrorism: preparedness varied across state and local jurisdictions (DHHS Publication No. GOA 03-373). Washington: U.S. Government Printing Office; 2003.

4. Meyer R, Morse S. Bioterrorism preparedness for the public health and medical communities. Mayo Clin Proc 2002;77:619-21.

5. Gallo R, Campbell D. Bioterrorism: challenges and opportunities for local health departments. J Public Health Manag Pract 2000;6:57-62.

6. National Association of Counties. Counties Secure America: A Survey of County Public Health Needs and Preparedness, 2002 [online, accessed 10 May 2004]. Available from: URL: bttp://www.naco.org/Contents/ContentGroups/ Publications1/Surveys1/Public_Health1/1447pubblth.pdf

7. National Association of County and City Health Officials. Research brief: assessment of local bioterrorism and emergency preparedness, No. 5, October 2001 [online, accessed 10 May 2004]. Available from: URL: $b t t p: / /$ www.naccho.org/documents/BT_brief1.pdf

8. Rosenthal L. Bioterrorism: a survey assessing the level of awareness among Alachua County's physicians, 2003 [online, accessed 5 Apr 2005]. Available from: URL: $h t t p: / /$ www.flabec.org/nfahec/chs/2003/Lee.pdf

9. Bottles K. We are all in this together: terrorism and the physician executive. Physician Exec 2002;28:59-62.

10. Hamburg M. Bioterrorism: responding to an emerging threat. Trends Biotechnol 2002;20:296-8.

11. Hyams K, Murphy F, Wessely S. Responding to chemical, biological, or nuclear terrorism: the indirect and longterm health effects may present the greatest challenge. J Health Polit Policy Law 2002;27:273-91.

12. Texas Department of Health. Anthrax "threat" guidance physicians and hospitals, 2001 [online, accessed 10 May
2004]. Available from: URL: http://www.dshcs.state.tx.us/ bioterrorism/Threat_Docs_hosp.htm

13. Flowers L, Mothershead L, Blackwell T. Bioterrorism preparedness. II: the community and emergency medical services systems. Emerg Med Clin North Am 2002;20:457-76.

14. Alder S, Clark J, White GL Jr, Talboys S, Mottice S. Physician preparedness for bioterrorism recognition and response: a Utah-based needs assessment. Disaster Manag Response 2004;2:69-74.

15. Woods R, McCarthy T, Barry M, Mahon B. Diagnosing smallpox: would you know it if you saw it? Biosecur Bioterror 2004;2:157-63.

16. Lee E. Bioterrorism: a survey assessing the level of awareness among Alachua County's physicians, 2003. Available from: http://www.flahec.org/nfahec/chs/2003/ Lee.pdf. Accessed January 7, 2004.

17. Alexander G, Wynia M. Ready and willing? Physicians' sense of preparedness for bioterrorism. Health Aff (Millwood) 2003;22:189-97.

18. Terndrup T, Nafziger S, Weissman N, Casebeer L, Pryor E. Online bioterrorism continuing medical education: development and preliminary testing. Acad Emerg Med 2005; 12:45-50.

19. Los Angeles County Department of Health ServicesPublic Health. Bioterrorism Expert Survey [online, accessed 16 Jan 2004]. Available from: URL: https://abweb. lapublichealth.org/phcommon/public/BTES/BTESForm.cfm

20. Wetter D, Daniell W, Treser C. Hospital preparedness for victims of chemical and biological terrorism. Am J Public Health 2001;91:710-6.

21. Schur C, Berk M, Mueller C. Perspectives of rural hospitals on bioterrorism preparedness planning. Policy Anal Brief W Ser 2004;(4):1-6.

22. Schultz C, Mothershead J, Field M. Bioterrorism preparedness I: the emergency department and hospital. Emerg Med Clin N Amer 2002;20:437-55. 